\title{
Evaluation of serum transaminase level as diagnostic tool for assessing hepatic disease conditions among chronic hepatitis B patients in Bangladesh
}

\author{
Fahmi Md Shaief ${ }^{1}$, SM Sabbir Alam ${ }^{1}$, Md Shahinul Alam², Mahmuda Yasmin ${ }^{1}$, CR Ahsan ${ }^{1}$ and Jamalunnessa ${ }^{1 *}$ \\ ${ }^{1}$ Deptartment of Microbiology, University of Dhaka, Dhaka-1000, Bangladesh, ${ }^{2}$ Department of Hepatology, Bangabandhu Sheikh Mujib Medical University, \\ Dhaka-1000, Bangladesh
}

\begin{abstract}
Chronic hepatitis $B$ (CHB) is a major infectious disease which frequently involves liver injury and could be serious, even life threatening. Complications mainly include the development of chronic liver disease (CLD), cirrhosis, hepatocellular carcinoma (HCC), and liver failure. Liver function tests like determining the level of serum alanine aminotrasnferase (ALT), aspertate aminotransferase (AST) are orthodoxly used to assess the inflammatory activity and cirrhotic process in the liver. A total 2453 patients with an age range of 12-86 years with a positive HBsAg serostatus for more than six months was included in this study. Among them hepatic disease conditions were confirmed for 952 patients using visible symptoms, histological findings and precutaneous liver biopsy. Patients were examined for the serum ALT and AST level as biochemical markers, HBeAg and anti-Hbe level as serological markers, and HBV DNA level as molecular marker. In this study it was found that the probability to have a raised level of ALT and AST increases as the disease progresses from less severe to more severe conditions. Almost $80 \%$ of the CHB patients were documented to contain a raised level of ALT and the ratio was found to be increased to $93 \%$ for patients with CLD and $100 \%$ in patients diagnosed with HCC. For AST, elevated level was found for $61 \%$ of CHB patients without liver complication and $97 \%$ of CLD patients. Among CLD patients, 91.7\% have raised level of both ALT and AST. And it was also found that the presence of serum $\mathrm{HBe} \mathrm{Ag}$ and Anti HBe antibody have a significant relationship with raised level of serum ALT, and AST. Significant relations were also found for raised level of DNA with higher level of serum ALT and AST. This study shows that there is significant correlations of serum ALT, AST level with hepatic disease conditions and other diagnosing markers like serum HBe Ag, Anti-HBe antibody and HBV DNA level.
\end{abstract}

Keywords: HBV diagnosis; Chronic infection; ALT and AST; HBe Ag and Anti-HBe antibody; DNA level; HBV disease condition

Hepatitis B is one of the major life threatening liver infection which is caused by the hepatitis B virus (HBV). It is a major global health problem and the most serious type of viral hepatitis and many of the affected individuals of HBV progress to chronic hepatitis, cirrhosis and hepatocellular carcinoma (HCC $)^{1,2}$. In Bangladesh, $36 \%$ of $\mathrm{HCC}$ is associated with hepatitis B infection. The main reason behind the fact that HBV infection is highly endemic in many of the third world countries and potentially progress to liver cirrhosis and HCC is that proper diagnosis of the infection and the disease state is very difficult with limited research settings ${ }^{3}$.

The presence or absence of Hepatitis B surface antigen (HBsAg), e antigen ( $\mathrm{HBeAg}$ ) and their respective antibodies at different stages of the disease and for different period of time are used as serological markers to define whether a person is chronically infected and having active viral replication or not ${ }^{4}$. Liver biopsy and liver function tests like determining the level of serum alanine aminotrasnferase (ALT), aspertate aminotransferase (AST), prothrombin time and albumin/globulin ratio can also be used to indirectly assess the inflammatory activity and cirrhotic process in the liver 5,6 .

The normal range of values for AST is from 5 to 40 units per liter of serum, while the normal range of values for ALT is from 7 to 56 units per liter of serum ${ }^{7}$. Patients with acute viral hepatitis can develop very high AST and ALT levels, sometimes in the thousands of units per liter. These high AST and ALT levels will become normal in several weeks or months as the patients recover completely from their acute hepatitis. In contrast, patients with chronic HBV and HCV infection typically have only mildly elevated AST and ALT levels, but these abnormalities can last years or decades ${ }^{8,9}$. Since most patients with chronic hepatitis are asymptomatic, their moderately abnormal liver enzymes are often unexpectedly found on routine blood tests while yearly physical exams or insurance physicals ${ }^{9}$.

Elevated blood levels of AST and ALT only means that the liver is inflamed, and elevations can be caused by many agents other

*Corresponding author:

Jamalunnessa, Deptartment of Microbiology, University of Dhaka, Dhaka-1000, Bangladesh E-mail: jamalun_nessa@hotmail.com 
than hepatitis viruses, such as medications, alcohol, bacteria, fungus, etc. In order to prove that a hepatitis virus is responsible for the elevations, blood must be tested for antibodies to each of the hepatitis viruses as well as for their genetic material ${ }^{9,10}$.

Conventionally, serum $\mathrm{HBeAg}$ is thought to be associated with active $\mathrm{HBV}$ replication and the synthesis of complete virions and has been used to identify highly infectious hepatitis carriers ${ }^{11}$, 12. More recently quantitative estimation of serum HBV-DNA has been considered as an accurate and highly potent marker of HBV infection ${ }^{13,14}$. However, none of the above mentioned tests are without their limitations and problem arises in interpreting the results ${ }^{15}$.

Thus in a densely populated country like Bangladesh with poor diagnostic facilities and with a large number of people at the risk of getting infected with HBV, it is very important to find out the correlation between the level of different markers of the infection and the disease condition. These findings will help to precisely interpret different test results and establish a proper guideline to treat the infection.

A total of 2453 patients were included in this study. All of these patients were positive for HBsAg for more than six months and were characterized as $\mathrm{CHB}$ patients. Both male and female patients with the age range of 12-86 years were included in the study. Among these 2453 patients, 952 of chronic HBV patients was confirmed for specific disease conditions using visible symptoms, precutaneous liver biopsy and histological findings. Four patients from total study were identified as disease progressed to $\mathrm{HCC}$ and included in this study.

Five milliliter $(\mathrm{ml})$ of venous blood was collected from each of the subjects by the vacutainer blood collection system maintaining strictly aseptic precautions. Serum was prepared from the collected sample using anticoagulant like heparin, oxalate, and ethylene diamine tetra-acetic acid (EDTA). The concentration of $\operatorname{ALT}(n=2453)$ and AST $(n=1315)$ was measured automatically using the Bachtech Coulter automated analyzer. The presence or absence of HBeAg in the patient's serum $(n=2312)$ was determined by the double antibody sandwich principle based on ELISA qualitative detection in which polystyrene micro well strips are pre coated with monoclonal antibodies specific to $\mathrm{HBeAg}$. The presence of antibody to hepatitis B virus e antigen was detected $(\mathrm{n}=524)$ by the ELISA KIT "Wanati Hep.BV". This kit is an enzyme-linked immunosorbent assay for qualitative detection of anti-HBe in human serum or plasma. Real time PCR (RT-PCR) was used for quantification of HBV DNA in patient's $(n=2312)$ serum sample. RT-PCR was done with the Robogene Triple Hyb HBV DNA quantification kit for finding the copy number of HBV DNA present per amount of serum sample. Data are expressed as frequencies and percentages. Categorical variables were compared using a 2-sided chi-square test. $P$ values were calculated from each data tables. P values d" 0.005 were considered as significant. Data analysis was done by the SPSS software version 16.0 .

Of the 952 test patients, 856 were diagnosed to have a chronic hepatitis B without any remarkable liver associated complication and the rest 96 were identified to retain CLD. Among the CHB patients $(n=856), 58 \%$ possessed a raised level of both ALT and AST (Table 1). However, greater percentages (92\%) of CLD patients were reported to contain elevated level of serum transaminase. It could be anticipated that as the disease progresses from CHB to CLD the level of transaminase in blood tends to rise for majority of the cases. This finding conveys the idea that the percentage of patients with abnormal level of AST tends to increase significantly as the disease progresses to be more complicated. Among all the investigated patients, 61\% (521/ 856) of CHB patients, 97\% (93/96) of CLD patients and 100\% (4/ 4) of HCC patients possessed elevated level of AST. For ALT, $80 \%(688 / 856)$ of the CHB patients, $93 \%$ (90/96) of CLD patients and $100 \%(4 / 4)$ of HCC patients were documented to contain an elevated level.

Table 1. Distribution of serum AST and ALT level (either normal or raised) with different hepatic disease conditions among CHB patients

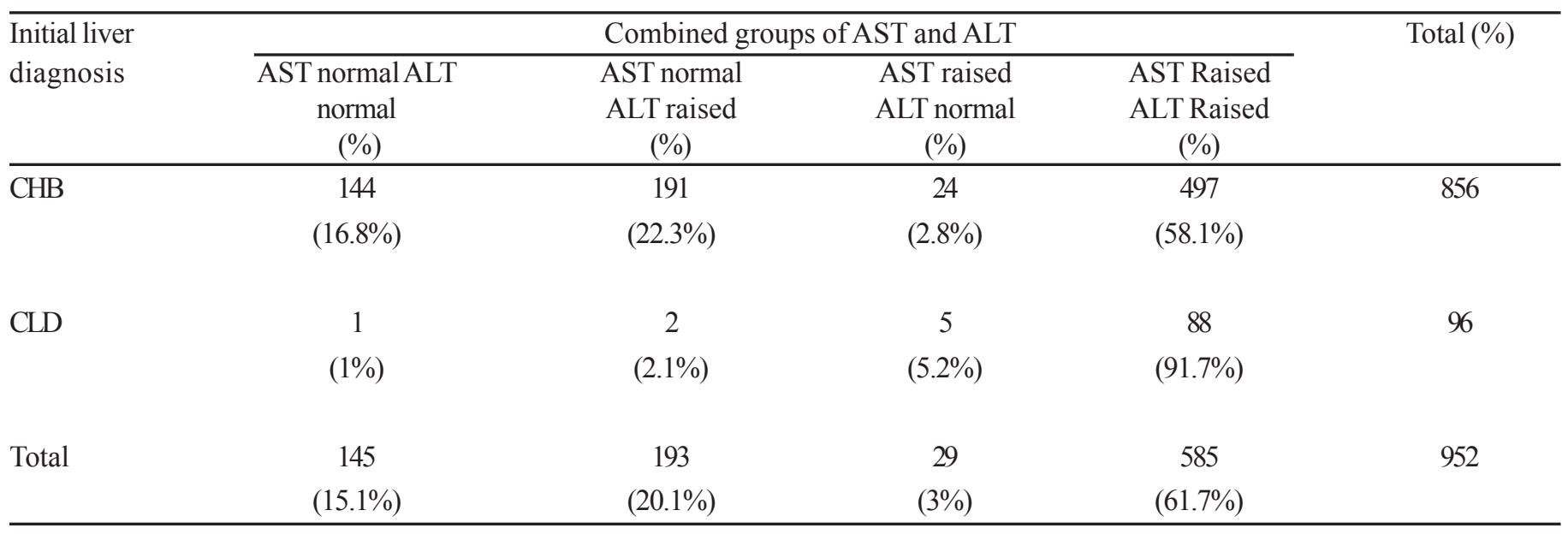


The AST/ALT ratio can be used to distinguish among different causes of hepatitis. A ratio of AST/ALT which is $<1$ usually indicates hepatitis from Hepatitis B virus infection. Whereas a ratio of AST/ALT which is greater than 1 but less than 2 usually indicates hepatitis from other non viral reasons like alcohol or other forms of liver injury. In this study, among $1310 \mathrm{HBsAg}$ positive patients tested majority (70.3\%) had an AST/ALT ratio of less than one.

After further analysis of 2312 patients, it was found that 1090 (47\%) hold HBeAg in their serum samples and the rest (53\%) were seronegative for $\mathrm{HBeAg}$. Among the $\mathrm{HBeAg}$ positive cases $(\mathrm{n}=1090)$, almost $90 \%$ had elevated level of ALT $(>40 \mathrm{U} / \mathrm{ml})$. However, when the subset of HBeAg negative cases $(n=1222)$ were further analyzed for their ALT status, comparatively lower proportion (73.8\%) of this subset were reported to contain raised level of serum alanine transaminase. The overall analysis shows significant association $(\mathrm{p}=<0.0001)$ between $\mathrm{HBeAg}$ seropositivity and elevated ALT level. For AST, among the 632 HBeAg positive cases (nearly $75 \%$ ) had a raised level of AST (>40 U/L) whether $683 \mathrm{HBeAg}$ negative cases (53.3\%) had an elevated AST level in serum samples. Significant relationship $(p=<0.0001)$ was observed between positive HBeAg serostatus and raised level of AST.

For anti-HBe, it was found that $74 \%$ ( $\mathrm{n}=995)$ of the patients with a positive anti-HBe serostatus had a raised level of ALT while $88 \%(876 / 995)$ of anti-HBe negative individuals had raised level of ALT. For AST, among the 407 study subsests 154 (53.7\%) of positive anti-HBe serostatus have a raised AST level and 73.5\% of anti-HBe negative cases have a raised AST level.This indicates that anti-HBe negative cases are more likely $(\mathrm{p}=<0.0001)$ to have a raised AST level than anti-HBe positive cases. The AST/ALT ratio did not differ significantly $(p=1.00)$ between $\mathrm{HBeAg}$ positive and negative individuals.

The level of HBV DNA was determined for 2312 patients. The level of HBV DNA can be classified into two categories: i) patients with a DNA load less than $10^{5} \mathrm{copies} / \mathrm{ml}$ were considered to have inactive chronic hepatits B infection and ii) patients with a DNA load greater than $10^{5} \mathrm{copies} / \mathrm{ml}$ were considered to have actively chronic HBV infection. It was found that 1524/1846 (82.6\%) patients of elevated ALT level had a HBV DNA quantity greater than $10^{5}$ copies $/ \mathrm{ml}$. This finding suggests that an elevated level of ALT is significantly $(\mathrm{p}=<0.0001)$ associated with higher HBV DNA level. It was found that $700(85.60 \%)(n=823)$ patients with high level AST also had a high level of HBV DNA $\left(>10^{5}\right)$. So, raised level of AST is also strongly correlated ( $p$ value $<0.0001$ ) with high level of HBV DNA replication.

HBV poses a huge burden on the health of Bangladeshi population, being the leading cause of all forms of CLD. Studies have shown that $\mathrm{HBV}$ is responsible for $33.3 \%$ of cases of HCC in Bangladesh ${ }^{3}, 61 \%-80 \%$ in India and 59\%-67\% in Pakistan ${ }^{16}$. Being in developing region of the world, Bangladesh holds poor diagnostic facilities. Furthermore, in this densely populated country with a large number of people at high risk of getting infected with HBV, it is of prime significance to locate the correlation among the level of different markers of the hepatitis B infection, relevant disease status and further prognosis. Nevertheless, those findings could facilitate better interpretation of the diverse test results and the establishment of a proper guideline for successful treatment of the infection and disease. Although liver histology still remains as the foundation of hepatitis activity investigation, it is an invasive procedure that is not without its complications ${ }^{1}$. Alternative liver function tests, such as, liver transaminases, prothrombin time and serum albumin/ globulin estimation, may be used to assess indirectly the inflammatory activity and cirrhotic process in the liver. This study aimed to study the ALT and AST level in serum as a diagnostic tool for diagnosing hepatic disease condition and find its relevance with serological and molecular markers. The risk of developing liver complications from chronic HBV infection increases with increasing concentrations of $\mathrm{ALT}^{17}$. Yuen and his colleagues had followed 3,233 Chinese patients with chronic HBV infection for approximately four years. According to their report, risk of developing complications from liver disease increased as ALT concentration increased from less than 0.5 times the upper limit of normal (ULN) to two to six times the ULN; ALT levels one to two times the ULN were associated with the highest risk of development of complications ${ }^{17}$.

The ratio of aspartate transaminase to alanine transamianse (AST/ ALT ratio) can be used to differentiate between dissimilar etiological basis of hepatitis. A ratio of AST/ALT which is $<1$ usually identifies Hepatitis B and C patients among jaundice patient pool, whereas a ratio of AST/ALT greater than 1 but less than 2 is usually indicative of hepatitis cases from nonviral reasons like alcohol or other forms of liver injury. Majority (70.3\%) of our study population had an AST/ALT ratio of less than one and indicative of alcohol independent liver damage ${ }^{18,19}$.

It was also found that presence of serum $\mathrm{HBe} \mathrm{Ag}$ and $\mathrm{Anti} \mathrm{HBe}$ antibody have a significant relationship with raised level of serum ALT, and AST. It showed a significant relationship for both elevated level of serum $\mathrm{HBe} \mathrm{Ag}$ and Anti $\mathrm{HBe}$ antibody with elevated level of serum AST and ALT. Our study here contradicts with a pervious study of Jie Shao et. al., 2007, where they don't find any significant correlation among serum $\mathrm{HBe} \mathrm{Ag} / \mathrm{Ab}$ with ALT, AST level ${ }^{20}$.

The quantification assay of serum HBVDNA by RT-PCR has been considered to be an accurate and reliable marker of HBV replication as it directly reflects the level of intrahepatic viral replication ${ }^{13,14}$. Nevertheless, HBV-DNA estimation is expensive and many laboratories in developing countries lack the logistical support required for the test. To compensate those situations, AST assay can be used since it has been labeled as one of the best predictors of the hepatitis activity index and chronic active hepatitis ${ }^{21}$. Eighty percent of chronic hepatitis B patients was documented to possess higher level of serum alanine transaminase. Among 
these patients with elevated ALT level, $82.6 \%$ had a HBV DNA quantity greater than $10^{5}$ copies $/ \mathrm{ml}$. This finding suggests that a higher level of ALT is significantly ( $\mathrm{p}=<0.0001$ ) associated with active viral replication in human population and that's why chronic Hepatitis B patients with a raised ALT level are more likely to develop life threatening liver complications.

During assessment of liver disease due to hepatitis, serum AST and ALT levels are most commonly used serum markers to detect acute and chronic hepatocytes cytotoxicity. Almost eighty percent of the CHB patients were documented in this report to contain a raised level of ALT. Among all the investigated CLD patients, $97 \%$ possessed elevated level of AST whereas raised level of AST was detected in $61 \%$ of the patients with CHB without liver complication. $58 \%$ of CHB patients possessed a raised level of both ALT and AST. However, greater percentages (92\%) of CLD patients were reported to contain elevated level of serum transaminase only. It could be anticipated that as the disease progresses from CHB to CLD the level of transaminase in blood tends to rise for majority of the cases. Yuen and his group (2001, 2005) reported previously that the risk of developing liver complications from chronic HBV infection enhances with increasing concentrations of ALT $^{17,22}$. Elevated AST levels have been reported elsewhere to be predominant in liver cirrhosis cases with increased ALT levels as well ${ }^{23}$. This study strengthens the inference that, there is significant correlation of serum ALT, AST level with hepatic disease progressions and other diagnosing markers like serum HBe Ag, Anti-HBe antibody and HBV DNA level.

\section{Acknowledgement}

We acknowledge the kind support of Bangabandhu Sheikh Mujib Medical University (BSMMU), Dhaka, Bangladesh to this work.

\section{Conflicts of interest}

As far as our concern there is no competing interests for concern.

\section{References}

1. Sherlock S and Dooley J. (eds). 2001. Hepatitis B Virus and Hepatitis Delta Virus, in Diseases of the Liver and Biliary System, Eleventh Edition, Blackwell Science Ltd, Oxford, UK.

2. De Martel C, Maucort Boulch D, Plummer M and Franceschi S. 2015. World wide relative contribution of hepatitis B and $\mathrm{C}$ viruses in hepatocellular carcinoma. Hepatology. 62(4): 1190-200.

3. Khan M and Ahmed N. 1996. Seroepidemiology of HBV and HCV in Bangladesh. Intern Hepatol Commun. 5: 27-9.

4. Hoofnagle JH, Dusheiko GM, Seeff LB, Jones EA, Waggoner JG and Bales ZB. 1981. Seroconversion from hepatitis B e antigen to antibody in chronic type B hepatitis. Annals of Inter Med. 94(6): 744-748.

5. Castera L. 2012. Noninvasive methods to assess liver disease in patients with hepatitis B or C. Gastroenterology. 142(6): 1293-302.

6. Spradling PR, Bulkow L, Teshale EH, Negus S, Homan C, Simons B, and McMahon BJ. 2014. Prevalence and causes of elevated serum aminotransferase levels in a population-based cohort of persons with chronic hepatitis B virus infection. $J$ Hepatol. 61(4):785-91.

7. Edoardo G, Botta F, Fasoli A, Ceppa P, Risso D, Lantieri PB, Celle G and Testa R. 1999. Progressive liver functional impairment is associated with an increase in AST/ALT ratio. Dig Dis and Sci. 44(6): 1249-1253.

8. Sheth SG, Flamm SL, Gordon FD and Chopra S. 1998. AST/ALT ratio predicts cirrhosis in patients with chronic hepatitis $\mathrm{C}$ virus infection. The Am J of Gastro. 93(1)44-48.

9. Liaw, Yun-Fan and Chia-Ming Chu. 2009. Hepatitis B virus infection. The Lancet. 373: 582-592.

10. Kuo, Chung-Huang, Tai D, Chang-Chien CS, Lan CK, Chiou SS and Liaw YF. 1992. Liver biochemical tests and dengue fever. Amer J Tro Med and Hyg. 47(3): 265-270.

11. Negro F, Chiaberge E, Oliviero S, et al. 1984. Hepatitis B virus DNA (HBV-DNA) in anti-HBe positive sera. Liver. 4:177-83.

12. Lieberman HM, Labrecque DR, Kew MC, Hadziyannis SJ and Shafritz DA. 1983. Detection of Hepatitis B virus DNA directly in human serum by a simplified molecular hybridisation test: comparison to $\mathrm{HBeAg} / \mathrm{Anti}-\mathrm{HBe}$ status in HBsAg carriers. Hepatology. 3: 285-91

13. Chen CJ, Yang HI, Su JUN, Jen CL, You SL, Lu SN, Huang GT, Iloeje UH and Reveal HBV Study Group. 2006. Risk of hepatocellular carcinoma across a biological gradient of serum hepatitis B virus DNA level. Jama. 295(1): 65-73.

14. Brechot C, Hadchouel M, Scotto J, Degos F, Charnay P, Trepo C and Tiollais P. 1981. Detection of hepatitis B virus DNA in liver and serum: a direct appraisal of the chronic carrier state. The Lancet. 318(8250): 765-768.

15. Gitlin N. 1997. Hepatitis B: diagnosis, prevention, and treatment. Clinical Chemistry. 43(8): 1500-1506.

16. Tandon BN, Acharya SK and Tandon A. 1996. Epidemiology of hepatitis B virus infection in India. Gut.38(Sppl. 2): S56-S59.

17. Yuen MF, Hui CK, Cheng CC, Wu CH, Lai YP and Lai CL. 2001. Long-term follow-up of interferon alfa treatment in Chinese patients with chronic hepatitis B infection: the effect on hepatitis B e antigen seroconversion and the development of cirrhosis-related complications. Hepatology. 34:139-145

18. Williams AL and Jay H. Hoofnagle. 1988. Ratio of serum aspartate to alanine aminotransferase in chronic hepatitis. Relationship to cirrhosis. Gastroenterology. 95(3): 734-739.

19. Giannini E, Botta F, Fasoli A, Ceppa P, Risso D, Lantieri PB, Celle G and Testa R. 1999. Progressive liver functional impairment is associated with an increase in AST/ALT ratio. Dig Dis and Sci. 44(6): 1249-1253.

20. Shao J, Wei L, Wang H, Sun Y, Zhang LF, Li J and Dong JQ. 2007. Relationship between hepatitis B virus DNA levels and liver histology in patients with chronic hepatitis B.World $J$ Gastroenterology. 13(14):2104-2107.

21. Borg TF, Frank and Jones EA. 1998. Prediction of hepatic inflammatory activity in hepatitis B. The Lancet. 352(9139): 1555.

22. Yuen MF, Yuan HJ, Wong DKH, Yuen JCH, Wong WM, Chan AOO, Wong BCY, Lai KC and Lai CL. 2005. Prognostic determinants for chronic hepatitis B in Asians: therapeutic implications. Gut. 54:16101614 .

23. Alam S, Ahmad N, Alam K, Mustafa G and Khan M. 2008. Correlation between hepatitis B viral DNA load and extent of liver pathology in patients with chronic hepatitis B.Hepatitis Monthly. 8(3): 185-189. 